\title{
Substitution of a Dysfunctional pAMT Allele Results in Low-Pungency but High Levels of Capsinoid in Capsicum chinense 'Habanero'
}

\author{
Siyoung Jang, Koeun Han, Yeoung Deuk Jo, Hee-Jin Jeong, Muhammad Irfan Siddique, Byoung-Cheorl Kang* \\ Department of Plant Science and Plant Genomics and Breeding Institute, Seoul National University, Seoul 151-921, Korea
}

\begin{abstract}
Capsinoids are the class of secondary metabolites identified in non-pungent peppers exhibiting the same bioactive properties as capsaicinoid. Previously, it has been demonstrated that capsinoid production is controlled by the capsaicin synthase (CS) gene and the putative-aminotransferase ( $p A M T)$ gene. In this study, we report that $C$. chinense 'SNU11-001' containing high levels of capsinoid has an early stop codon in $p A M T$ resulted from $403 \mathrm{bp}$ and $8 \mathrm{bp}$ insertions deletion in the third and sixth exons. In order to know whether $C S$ expression is correlated with the level of capsinoid, CS and $p A M T$ expressions were determined using SNU11-001 and four Capsicum accessions with different pungency level. RT-PCR analysis showed higher transcription levels of $C S$ in pungent accessions but no clear differences in $p A M T$ expression. To investigate the effect of the substitution of the $p A M T$ allele of $C$. chinense 'Habanero' with the dysfunctional $p A M T$ allele of SNU11-001, an $\mathrm{F}_{2}$ population was constructed by a cross between aforementioned parental lines. Molecular markers were developed to distinguish $C S$ and $p A M T$ genotypes of SNU11-001 and Habanero and $\mathrm{F}_{2}$ plants were genotyped. All $\mathrm{F}_{2}$ plants having the $p A M T$ genotype of SNU11-001 contained high levels of capsinoid while very low levels of capsaicinoid. There was no significant difference in levels of capsinoid among the $\mathrm{F}_{2}$ plants regardless of $C S$ genotypes. This may be due to strong $C S$ expression of both parental lines. In conclusion, our results show that it is possible to develop a new Habanero cultivar with high capsinoid content by introducing a dysfunctional $p A M T$ allele.
\end{abstract}

Keywords Capsaicinoid, Capsinoid, Capsiate, pAMT, CS, SNU11-001

\section{INTRODUCTION}

The pungency is a unique characteristic of genus Capsicum caused by capsaicinoids in fruits. Capsaicinoids are alkaloids derived from placenta tissues of pepper and contain many biomedical functions such as antioxidation, cancer prevention, weight reduction, and cardiovascular regulation (Thiele et al. 2008; Xiu-Ju et al. 2011). Capsaicin, one of the capsaicinoid analogues, is synthesized by capsaicin synthase $(C S)$ through condensation of vanillyl amine derived from the phenylpropanoids pathway and 8-methyl-6-nonenoic acid from the valine pathway. Vanillin is converted to vanillylamine by putative aminotransferase (pAMT) (Xiu-Ju et al. 2011).

Capsinoid, capsaicinioid-like substance was first reported by Yazawa in 1989. Capsiate, one of the capsinoid analogues, has the same structure as capsaicin except for replacement of a peptide bond $(\mathrm{NH})$ by an ester bond $(\mathrm{O})$. The replacement of peptide bond with ester bond causes nonpungency or low-pungency of capsinoid. Low-pungency of capsiate makes it more palatable and less toxic than capsaicin. Capsinoid are unstable and easily degraded in the aqueous phase. Therefore, capsinoid has advantage over capsaicinoid in biomedical uses (Sharma et al. 2013) .

Several genetic studies have been conducted on biosynthesis of capsinoid. Biosynthesis of capsinoid is caused by mutations in the $P A M T$ gene resulting in suppression of the formation vanillylamine from vanillin (Lang et al. 2009; Tanaka et al. 2010a). Dysfunction of pAMT shunts synthesis vanillylamine into vanillyl alcohol. Tanaka et al. (2010) identified several loss-of-function in $p A M T$ alleles that rendered production of capsinoid in pepper. Capsaicin

Received Jun 17, 2015; Revised Jun 23, 2015; Accepted Jun 25, 2015; Published June 30, 2015

*Corresponding author Byoung-Cheorl Kang, bk54@snu.ac.kr, Tel: +82-2-880-4563, Fax: +82-2-873-2056 
synthase encoded by the Pun1 locus is required for biosynthesis of both capsaiciniod and capsinoid (Han et al. 2013).

Quatitative control of capsinoid synthesis can be affected by other factors besides $P A M T$ and CS. Capsaicinoid accumulation is affected by environmental conditions and genetic constitutions. Genetic studies on capsaicinoid content have been conducted using QTL analysis and molecular mapping. Six QTLs in capsaicinoid accumulation were identified explaining $31 \%$ of the phenotypic variation (Ben-Chaim et al. 2006). The same genetic factors controlling capsaicinoid accumulation may be involved in capsinoid accumulation. Genetic study of capsinoid biosynthesis has been performed since capsinoid was discovered in 1980s. However, quantitative control of capsinoid in pepper has not been elucidated.

The purpose of this research was to investigate the genetic factors affecting capsinoid accumulation and to test the possibility to develop a new Habanero cultivar with high capsinoid content by introducing a dysfuctional $p A M T$ allele. To achieve the objectives, analysis of capsaicinoid and capsinoid content and genotype analysis of $p A M T$ and $C S$ were performed in an $\mathrm{F}_{2}$ population derived from crossed between $C$. chinense 'SNU11-001' and C. chinense 'Habanero'.

\section{MATERIALS AND METHODS}

\section{Plant materials}

A total of six Capsicum cultivars containing different levels of capsaicinoid and capsinoid were used. $C$. chinense 'SNU11-001' contains the highest level of capsinoid and the lowest level of capsaicinoid. C. annuиm 'Early Calwonder (ECW)' produces no capsaicinoid and capsinoid. C. annuиm 'Yuwol-cho' and C. annuиm 'Takanotsume', which are Korean and Japanese landraces, respectively, have mild pungency. C. chinense 'Habanero' and 'Jolokia' are very pungent cultivars.

SNU11-001 and Habanero were used to construct a mapping population. Nine $F_{1}$ and $215 \mathrm{~F}_{2}$ plants were grown in Seoul National University farm (Suwon, Korea).

\section{$p A M T$ and $C S$ genotype analysis}

For genotyping of $p A M T$ of SNU11-001, two types of molecular markers were developed. To design SCAR markers, $p A M T$ sequence was obtained from $C$. аппиит genome database (http://cab.pepper.snu.ac.kr). The first primer set, at the third intron $\mathrm{F}$ and $\mathrm{R}$, was designed to detect insertion of repeat sequence on the third intron of the pAMT gene which is specific to $C$. chinense. The second marker, the third intron $T c c-\mathrm{R} 3$ and third intron (R), was designed to detect the transposable element on the third intron in the $P A M T$ gene which is specific to SNU11-001.

To distinguish the CS genotype between SNU11-001 and Habanero, two CAPS markers were developed. First marker was designed in the first exon using Alul site and the other marker was designed in the second exon using Rsal site. The latter marker was used for the $C S$ genotyping, since it showed clearer band pattern than the former.

To determine the pAMT genotype of SNU11-001, polymerase chain reaction was performed in a $25 \mu 1$ final volume containing $50 \mathrm{ng}$ template DNA concentration, 10 pmol of reverse and forward primers, dNTP, 10x Hipi buffer and 1 unit of Taq polymerase.

PCR was performed with following conditions: $94^{\circ} \mathrm{C}$ preheating for 5 minutes followed by 35 cycles of $94{ }^{\circ} \mathrm{C}$ for 30 seconds, $60^{\circ} \mathrm{C}$ for 30 seconds, $72^{\circ} \mathrm{C}$ for 1 minutes and a final extension of 10 minutes at $72{ }^{\circ} \mathrm{C}$. PCR condition to determine the $C S$ genotype was similar to that of the $p A M T$ genotype analysis. Except the annealing temperature which was standardized at $57^{\circ} \mathrm{C}$.

\section{DNA extraction}

Total genomic DNA was extracted from young leaves by CTAB method as described previously (Han et al. 2013). Nanodrop (Nanodrop Technology, Inc., Wilmington, DE, USA) was used to determine the concentration of genomic DNA. DNA samples were dissolved in the final volume of $30 \mu \mathrm{l}$ in TE buffer (pH7.0).

\section{RNA Isolation and cDNA synthesis}

Total RNA was isolated from the placenta 20 days after fruit setting by TRIzol reagent (Invitrogen, Korea) method (Han et al. 2013). RNA samples were diluted in RNAse- 
free water (Hybrid-R, GeneAll Biotechnology, Seoul, Korea). RNA concentration was measured at Nanodrop. To synthesize cDNA, reverse-transcriptional PCR was performed in a $20 \mu \mathrm{l}$ PCR volume containing M-MLV 5x reaction buffer, dNTP, M-MLV RT 200 units and mixture of mRNA and oligo dT for 1 hour at $42^{\circ} \mathrm{C}$.

\section{HPLC analysis of capsaicinoid and capsinoid}

Three fruits from individual plants were harvested from all Capsicum accessions and SNU11-001 x Habanero $\mathrm{F}_{1}$ and $F_{2}$ plants. Whole fruits including seeds were chopped and stored at $-20^{\circ} \mathrm{C}$. HPLC analysis was performed in the Foundation of Agri. Tech. Commercialization and Transfer (FACT, Suwon, Korea) according to the method described by Han et al. (2013).

\section{RESULTS}

\section{Capsaicinoid and capsinoid content of the five cultivars}

HPLC analysis was executed to measure capsaicinoid and capsinoid concentrations of five cultivars; SNU11-001, ECW, Yuwol-cho, Takanotsume and Habanero (Table 1, Fig. 1). It was assumed that $C S$ transcriptional level might be correlated with capsaicinoid content. Capsaicinoid and capsinoid content were measured at four different stages. Habanero contained the highest capsaicinoid concents $(9195.3 \pm 591.29 \mu \mathrm{g} / \mathrm{gDW})$ among five cultivars at stage 2 . Yuwol-cho and Takanotsume showed similar capsaicinoid levels, $3433.52 \pm 588.23 \mu \mathrm{g} / \mathrm{gDW}$ and $3153.73 \pm 518.04$ $\mu \mathrm{g} / \mathrm{gDW}$, respectively. However, capsaicinoid content of Takanotsume was higher than those of Yuwol-cho at stage

Table 1. Comparison of capsaicinoid and capsinoid content in five cultivars by HPLC analysis.

\begin{tabular}{|c|c|c|c|c|c|c|c|c|}
\hline \multirow{2}{*}{$\begin{array}{l}\text { Capsicum } \\
\text { cultivars }\end{array}$} & \multirow{2}{*}{ Species } & \multirow{2}{*}{ Stage $\mathrm{e}^{\mathrm{y})}$} & \multicolumn{3}{|c|}{ Capsaicinoid ( $\mu \mathrm{g} / \mathrm{gDW})$} & \multicolumn{3}{|c|}{ Capsinoid ( $\mu \mathrm{g} / \mathrm{gDW})$} \\
\hline & & & Capsaicin & Dihydrocapsaicin & Total & Capsiate & Dihydrocapsiate & Total \\
\hline \multirow[t]{4}{*}{ SNU11-001 } & \multirow{4}{*}{$\begin{array}{c}\text { C. } \\
\text { chinense }\end{array}$} & 1 & $17.9 \pm 5.26$ & $15.5 \pm 4.79$ & $33.4 \pm 10.04$ & $2910.43 \pm 974.2$ & $647.85 \pm 138.33$ & $3558.28 \pm 1112.54$ \\
\hline & & 2 & $16.13 \pm 4.28$ & 0 & $16.13 \pm 7.15$ & $6106.47 \pm 1609.48$ & $749.52 \pm 186.96$ & $6855.98 \pm 1795.53$ \\
\hline & & 3 & $25.72 \pm 6.6$ & $24.36 \pm 11.4$ & $50.09 \pm 17.94$ & $6669.92 \pm 613.8$ & $771.88 \pm 90.47$ & $7441.81 \pm 693.84$ \\
\hline & & 4 & $17.72 \pm 5.08$ & $17.31 \pm 2.99$ & $35.03 \pm 7.94$ & $4352.9 \pm 925.64$ & $487.96 \pm 110.79$ & $4840.86 \pm 1032.86$ \\
\hline \multirow[t]{4}{*}{$\mathrm{ECW}$} & \multirow{4}{*}{$\begin{array}{c}C . \\
\text { annuиm }\end{array}$} & 1 & - & - & - & - & - & - \\
\hline & & 2 & $\mathrm{nd}^{\mathrm{x})}$ & nd & nd & nd & nd & nd \\
\hline & & 3 & nd & nd & nd & nd & nd & nd \\
\hline & & 4 & nd & nd & nd & nd & nd & nd \\
\hline \multirow[t]{4}{*}{ Yuwol-cho } & \multirow{4}{*}{$\begin{array}{c}C . \\
\text { annuum }\end{array}$} & 1 & $116.52 \pm 10.29$ & $125.45 \pm 4.09$ & $241.97 \pm 6.19$ & $87.59 \pm 3.58$ & $22.9 \pm 3$ & $110.48 \pm 0.59$ \\
\hline & & 2 & $1572.32 \pm 325.99$ & $1861.19 \pm 317.44$ & $3433.52 \pm 588.23$ & $273.17 \pm 145.78$ & $79.21 \pm 15.7$ & $352.37 \pm 159.43$ \\
\hline & & 3 & $717.43 \pm 84.11$ & $1063.48 \pm 152.96$ & $1780.9 \pm 235.44$ & $101.74 \pm 29.01$ & $18.81 \pm 2.89$ & $120.55 \pm 31.74$ \\
\hline & & 4 & $516.92 \pm 204.75$ & $841.51 \pm 186.46$ & $1358.44 \pm 391.21$ & $30.25 \pm 8.13$ & $12.53 \pm 0.27$ & $42.78 \pm 7.86$ \\
\hline \multirow[t]{4}{*}{ Takanotsume } & \multirow{4}{*}{$\begin{array}{c}C . \\
\text { annuиm }\end{array}$} & 1 & - & - & - & - & - & - \\
\hline & & 2 & $1632.78 \pm 203.98$ & $1520.95 \pm 322.53$ & $3153.73 \pm 518.04$ & $364.53 \pm 21.62$ & $85.46 \pm 8.32$ & $449.98 \pm 29.49$ \\
\hline & & 3 & $1362.76 \pm 92.97$ & $1563.18 \pm 161.88$ & $2925.93 \pm 324.81$ & $275.4 \pm 22.97$ & $82.58 \pm 7.09$ & $357.98 \pm 29.96$ \\
\hline & & 4 & $1780.93 \pm 174.57$ & $2172.31 \pm 359.59$ & $3953.24 \pm 399.23$ & $187.81 \pm 36.12$ & $40 \pm 6.76$ & $227.81 \pm 42.84$ \\
\hline \multirow[t]{4}{*}{ Habanero } & \multirow{4}{*}{$\begin{array}{c}C . \\
\text { chinense }\end{array}$} & 1 & $4771.1 \pm 677.47$ & $4211.51 \pm 474.46$ & $8982.62 \pm 1130.04$ & $470.63 \pm 83.72$ & $118.47 \pm 16.52$ & $589.1 \pm 99.95$ \\
\hline & & 2 & $4655.94 \pm 566.67$ & $4539.36 \pm 53.88$ & $9195.3 \pm 591.29$ & $488.82 \pm 102.01$ & $114.84 \pm 23.02$ & $603.66 \pm 128.81$ \\
\hline & & 3 & $2113.27 \pm 0^{*}$ & $2227.2 \pm 0^{*}$ & $4340.47 \pm 0^{*}$ & $169.34 \pm 0^{*}$ & $45.75 \pm 0^{*}$ & $215.1 \pm 0^{*}$ \\
\hline & & 4 & $2456.59 \pm 143.4$ & $2651.17 \pm 140.63$ & $5107.75 \pm 277.74$ & $255.44 \pm 59.45$ & $58.28 \pm 6.37$ & $313.71 \pm 65.54$ \\
\hline
\end{tabular}

\footnotetext{
${ }^{\text {z) }}$ nd $=$ not detected

${ }^{y)}$ stage, 1: 23 days after fruit set, 2: 30 days after fruit set, 3: 37 days after fruit set, 4: 45 days after fruit set

*indicates that this experiment was not repeated.
} 

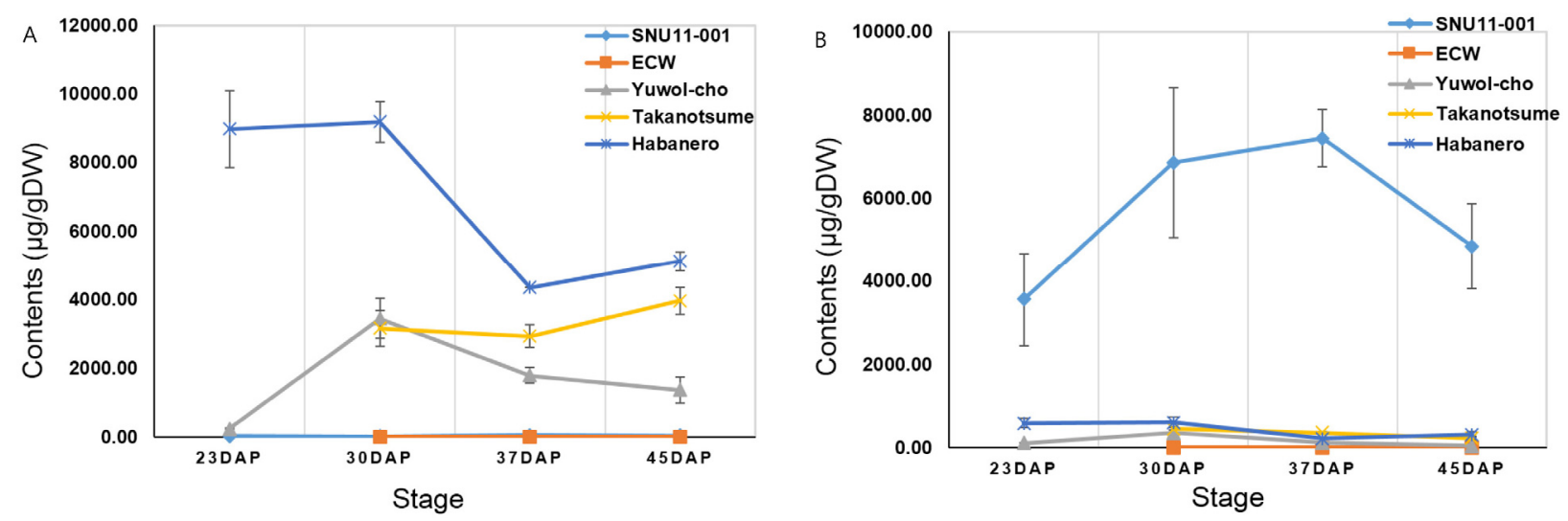

Fig. 1. Comparison of (A) capsaicinoid and (B) capsinoid content according to fruit developmental stages in five cultivars.

3 and 4. ECW and SNU11-001 was marked with nondetectable capsaicinoid (16.13 $\pm 7.15 \mu \mathrm{g} / \mathrm{gDW})$. On the other hand, the highest capsinoid level $(6855.98 \pm 1795.53 \mu \mathrm{g} / \mathrm{gDW})$ was detected in SNU11-001 followed by Habanero, whereas no capsinoid was detected in ECW.

\section{Construction of segregating populations for capsinoid study}

To investigate relationship between capsinoid production and Nonitalic activity, four $\mathrm{F}_{1}$ populations using SNU11-001 and four cultivars showing various levels of pungency (ECW, Yuwolcho, Takanotsume, Habanero) were constructed. In the interspecific crosses, C. annuum lines were used as a maternal parent and others as paternal parents to reduce the cross incompatibility. Only one $\mathrm{F}_{2}$ population was developed derived from the cross between SNU11-001 and Habanero due to interspecific cross incompatibility.

\section{pAMT and $C S$ expression pattems}

pAMT and $C S$ expression patterns were tested in five cultivars. The primers for $p A M T$ and $C S$ were designed using an allele-specific sequences. The cDNA of $p A M T$ and $C S$ were amplified as 1455 bp and 1206 bp in size, respectively. cDNAs were prepared from RNA extracted from fruits after 20 and 45 days after fruit set were used (Fig. 2).

$p A M T$ transcripts were amplified at immature stage in all cultivars. Two $p A M T$ transcripts with different sizes were detected in SNU11-001. The nonpungent cultivar ECW also expressed the $p A M T$ gene. However, at mature stage, no $p A M T$ expression was detected in all cultivars except Habanero. The CS gene was not expressed in ECW as expected. CS expression was detected in other cultivars including SNU11-001 at the immature stage. Habanero showed the highest $C S$ expression among the tested cultivars. By contrast, almost no CS transcript was detected at the mature stage in all cultivars.

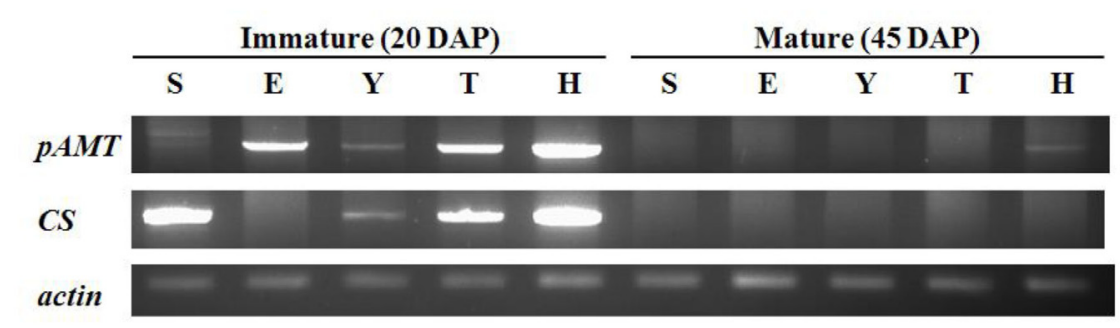

Fig. 2. $p A M T$ and $C S$ expression patterns in five cultivars by RT-PCR. Immature and mature stages correspond to 20 and 45 days after fruit set respectively. Actin was used as control. S SNU11-001, E ECW, Y Yuwol-cho, $T$ Takanotsume, $H$ Habanero. 


\section{cDNA sequence analysis of $p A M T$ and $C S$}

Two partial $p A M T$ transcripts were obtained from SNU11-001 (Fig. 3). The longer transcript 1,118 bp in size contained a $403 \mathrm{bp}$ insertion and 8 bp deletion in the third and sixth exons. The longer transcript was similar to that of Aji Dulce strain 2 (Tanaka et al. 2010b). The smaller transcript had $45 \mathrm{bp}$ deletion and $8 \mathrm{bp}$ insertions. Both transcripts contained an early stop codon.
To identify sequence differences of CS between SNU11001 and Habanero, full sequences of the coding region in both cultivars were obtained (Fig. 4) and 4 SNPs were identified. Three SNPs resulted in amino-acid changes but one was a synonymous mutation. First two non-synonymous mutations were located in the first exon whereas the other was occurred in the second exon.
A

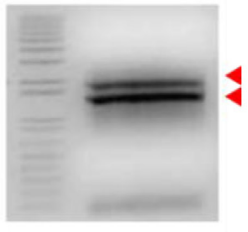

B

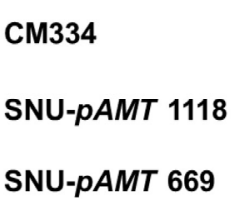

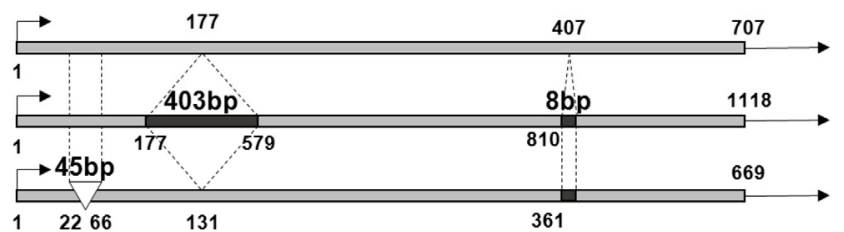

Fig. 3. Two types of loss-of-function $p A M T$ in SNU11-001. (A) Two types of $p A M T$ transcript were detected in SNU11-001. (B) The longer transcript contains a 403 bp insertion between the third and the fourth exons and another 8 bp insertion but smaller transcript has 45 bp deletion and 8 bp insertion.

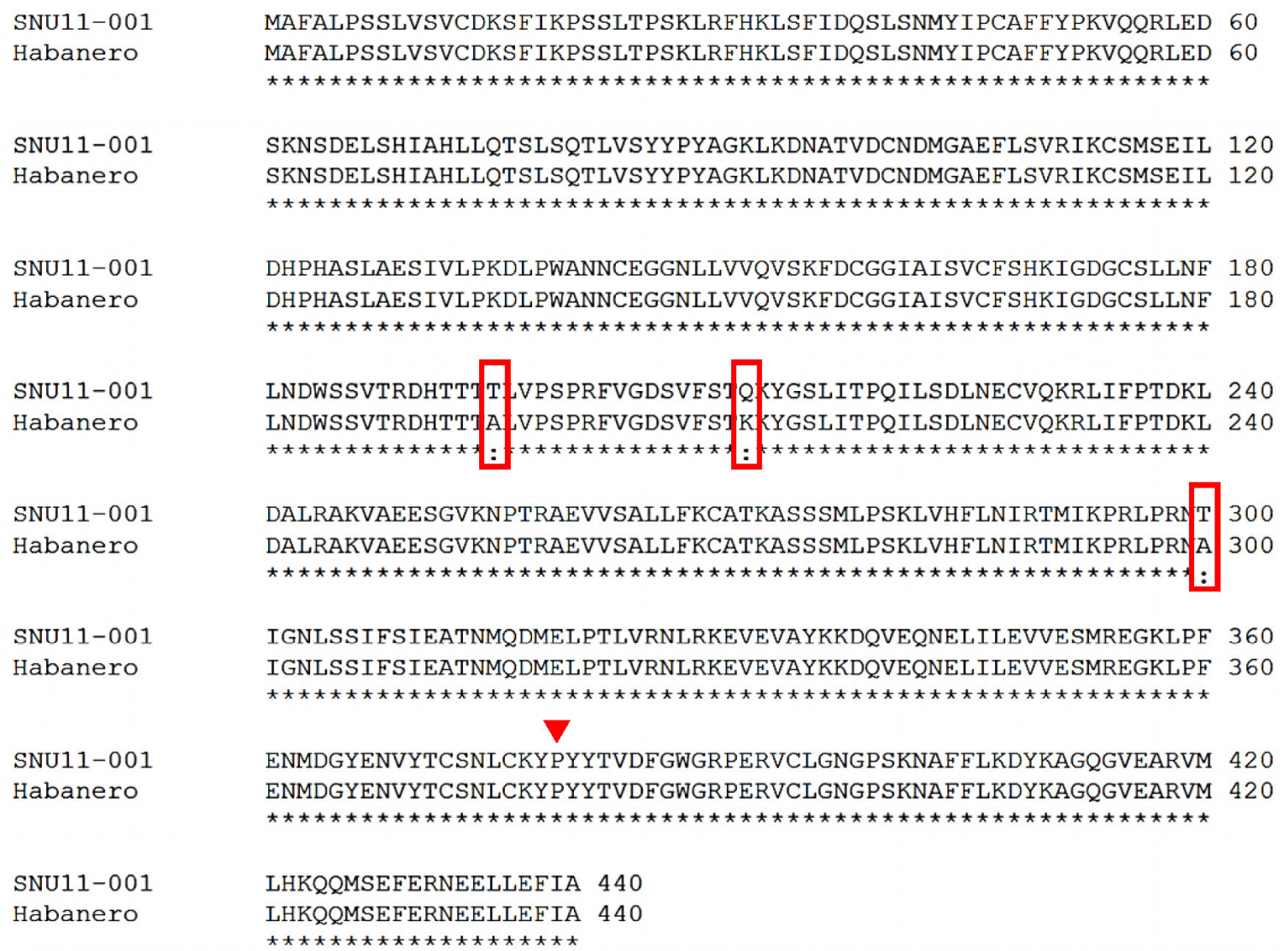

Fig. 4. Amino acid sequence alignment of the CS gene in SNU11-001 and Habanero. Four mutations were detected. Three of them in the box are non-synonymous mutation and another marked with triangle is synonymous mutation. 


\section{$p A M T$ and $C S$ marker development and genotype analysis}

Two molecular markers were designed. One marker was developed for the $P A M T$ gene to detect the $p A M T$ mutant and the other marker was based on the $C S$ gene to distinguish $C S$ of SNU11-001 and Habanero. pAMT marker was designated as SNU-pAMT669. The insertion of transposable element $(T c c)$ on the third intron of the $p A M T$ gene was specific to SNU11-001. This SCAR marker was developed from the sequence of $T c c$ in the third intron of
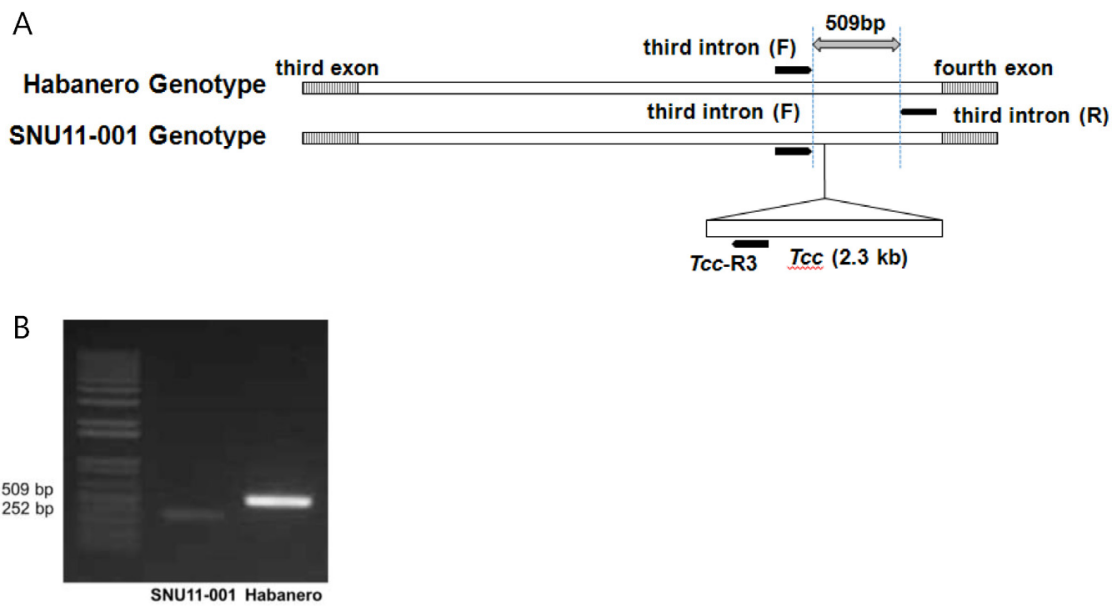

Fig. 5. Development of molecular markers to select $p A M T$ mutant. (A) The SCAR marker set was designed from the sequence of $T c c$ in the third intron of SNU11-001 to select $p A M T$ mutant plant. (B) PCR analysis of pAMT marker. Striped box corresponds to exon and black bar indicates marker.

A gDNA sequence alignment

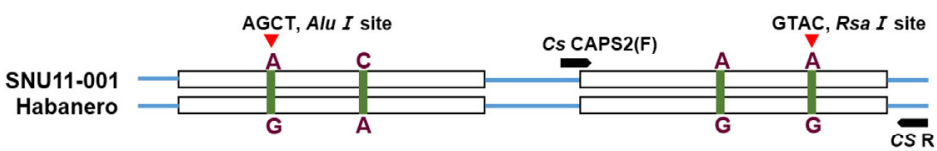

amino acid sequence alignment

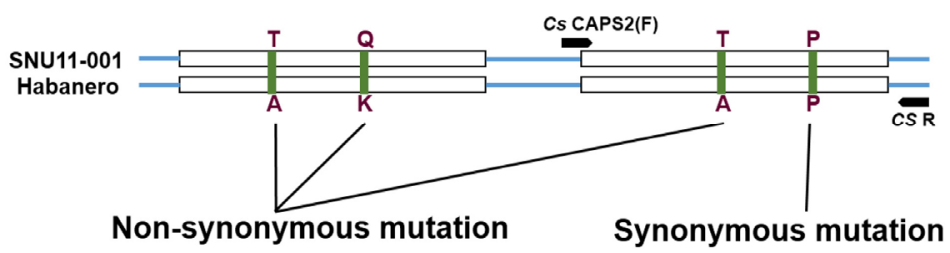

B

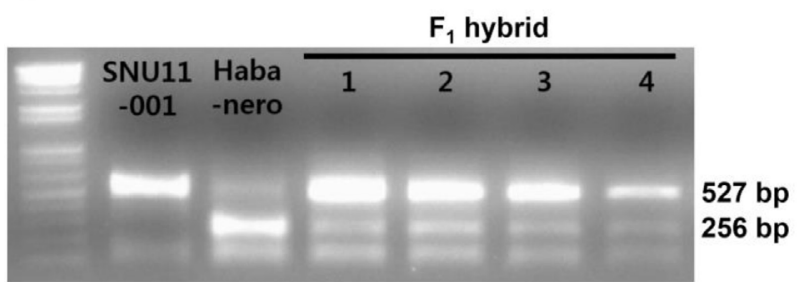

Fig. 6. Development of molecular markers to distinguish the CS genotypes of SNU11-001 and Habanero. (A) SNP position and restriction sites distinguishing SNU-001 and Habanero. The CAPS marker set was developed in the second exon using Rsa 1 site to distinguish CS genotypes of SNU11-001 and Habanero. (B) CS marker analysis using SNU-001, Habanero, and $\mathrm{F}_{1}$ hybrids 
SNU11-011 (Fig. 5). Therefore, the primer set differentiated pAMT mutant cultivars which contain Tcc element. On the other hand, $C S$ marker was developed to discriminate between normal $C S$ in two cultivars using a SNP (Fig. 6). This marker set was based on the synonymous mutation in second exon which can be detected by Rsal site. This CAPS marker was used to genotype $C S$ alleles in SNU11-001 x Habanero $\mathrm{F}_{2}$ population.

pAMT and CS genotyping analysis was performed for SNU11-001 x Habanero $F_{2}$ plant using SCAR and CAPS markers described above. Out of $215 \mathrm{~F}_{2}$ individuals, 76, 84, and 49 plants turned out to have $p A M T / p A M T, p A M T /$ pamt, and pamt/pamt genotypes, respectively (Table 2). Overall, the segregation ratio did not fit an expected ratio 1:2:1 $(\mathrm{p}<0.05)$ and the number of $p A M T /$ pamt heterozygote was less than expected. When $\mathrm{F}_{2}$ plants were subjected to $C S$ genotyping, $C S^{S} / C S^{S}, C S^{H} / C S^{H}$ and $C S^{S} / C S^{H}$ genotypes were 50, 150 and 108 , respectively (Table 3 ).

\section{Capsinoid and capsaicinoid content in plants having the pamt/pamt genotype}

Capsaicinoid and capsinoid content was measured for 42 pamt/pamt plants (Table 4). All tested plants contained very low levels of capsaicinoid whereas capsinoid content were relatively high ranging from $1485.61 \pm 115.58$ to $6050.75 \pm 698.74 \mu \mathrm{g} / \mathrm{gDW}$ (Table 4). Capsinoid content in plant No. 76 was marked approximately 4 times higher as compared to No. 170. Capsinoid content of No. 76 was comparable to that of SNU11-001 (Table 4).

Using the 42 pamt/pamt plants, correlation between the $C S$ genotype with capsinoid content was investigated. Capsinoid content in plants having $C S^{S} / C S^{S}, C S^{H} / C S^{H}$ and $C S^{S} / C S^{H}$ were $3033.95 \mathrm{~d}$ with, $2664.02 \pm 198.43$, and $2933.66 \pm 309.53 \mu \mathrm{g} / \mathrm{gDW}$, respectively (Table 4 ). These results demonstrate that there is no significant difference in capsinoid content between $C S$ genotypes.

\section{DISCUSSION}

This research was conducted to investigate the genetic factors affecting capsinoid accumulation and to test the possibility to develop pepper cultivars with high capsinoid content by introducing a dysfuctional $P A M T$ allele. We showed that substitution of the $P A M T$ allele of 'Habanero' with the dysfuctional $P A M T$ allele of 'SNU11-001' results

Table 2. Genotype analysis of $p A M T$ and $C S$.

\begin{tabular}{|c|c|c|c|c|c|c|c|c|c|c|c|}
\hline \multirow{4}{*}{$\begin{array}{c}\mathrm{F}_{2} \\
\text { (SNU11-001 x } \\
\text { Habanero) }\end{array}$} & \multirow[b]{2}{*}{ Pop. size } & \multirow{2}{*}{$\begin{array}{l}\text { Expected } \\
\text { ratio }\end{array}$} & \multicolumn{3}{|c|}{ pAMT genotype } & \multirow{2}{*}{$\begin{array}{c}\chi^{2} \\
\text { (p value) }\end{array}$} & \multicolumn{3}{|c|}{$C S$ genotype } & \multirow{2}{*}{$\begin{array}{l}\text { Undeter- } \\
\text { mined }\end{array}$} & \multirow{2}{*}{$\begin{array}{c}\chi^{2} \\
\text { (p value) }\end{array}$} \\
\hline & & & $\begin{array}{l}\text { pamt/ } \\
\text { pamt }\end{array}$ & $\begin{array}{c}\text { pAMT/ } \\
\text { pamt }\end{array}$ & $\begin{array}{l}\text { pAMT/ } \\
p A M T\end{array}$ & & $C S^{S} / C S^{S}$ & $C S^{S} / C S^{H}$ & $C S^{H} / C S^{H}$ & & \\
\hline & & $1: 2: 1$ & 49 & 84 & 76 & $\begin{array}{c}14.7674 \\
(0.00062130)\end{array}$ & & & & 6 & \\
\hline & 215 & $1: 2: 1$ & & & & & 50 & 108 & 50 & 7 & $\begin{array}{c}0.308 \\
(0.8574)\end{array}$ \\
\hline
\end{tabular}

$C S^{S}$ indicates $C S$ of SNU11-001 type and $C S^{H}$ corresponds to $C S$ of Habanero type.

Table 3. Inheritance pattern of $p A M T$ and $C S$ in SNU11-001 x Habanero $\mathrm{F}_{2}$ population.

\begin{tabular}{cccc}
\hline \hline pAMT genotype & Number of individuals & $C S$ genotype & Number of individuals \\
\hline \multirow{2}{*}{ pamt/pamt } & \multirow{2}{*}{49} & $C S^{S} / C S^{S}$ & 14 \\
& & $C S^{S} / C S^{H}$ & 25 \\
& \multirow{2}{*}{160} & $C S^{H} / C S^{H}$ & 10 \\
\hline \multirow{2}{*}{ pAMT/pAMT } & & $C S^{S} / C S^{S}$ & 36 \\
& & $C S^{S} / C S^{H}$ & 83 \\
& & $C S^{H} / C S^{H}$ & 40 \\
\hline
\end{tabular}


- Plant Breed. Biotech. 2015 (June) 3(2):119 128

Table 4. Capsaicinoid and capsinoid content in pamt/pamt $\mathrm{F}_{2}$ plants with different $C S$ genotypes.

\begin{tabular}{|c|c|c|c|c|c|c|c|}
\hline \multirow{2}{*}{$\begin{array}{l}\text { pamt mutant } \\
\text { individual }\end{array}$} & \multirow{2}{*}{$C S$ type } & \multicolumn{3}{|c|}{ Capsaicinoid $(\mu \mathrm{g} / \mathrm{gDW})$} & \multicolumn{3}{|c|}{ Capsinoid $(\mu \mathrm{g} / \mathrm{gDW})$} \\
\hline & & Capsaicin & Dihydrocapsaicin & Capsaicinoid & Capsiate & Dihydrocapsiate & Capsinoid \\
\hline 6 & $C S^{S} / C S^{H}$ & 50.15 noid 7 & 56.64noid8 & 106.79oid.85 & 2461.66id50.09 & 628.466id & $3090.06 i d 53.29$ \\
\hline 15 & $C S^{H} / C S^{H}$ & $31.4806 \mathrm{id} 1$ & $38.6306 \mathrm{id} 8$ & $70.1106 \mathrm{id} 15$ & $1639.35 \mathrm{id} 80.97$ & 536.255 id. 65 & $2175.61 \mathrm{id} 27.96$ \\
\hline 18 & $C S^{S} / C S^{H}$ & $39.5561 \mathrm{id} 6$ & $46.9761 \mathrm{id} 46$ & $86.5261 \mathrm{id} 07$ & $2602.74 \mathrm{id} 10.73$ & 380.784id.37 & $2983.52 \mathrm{id} 28.45$ \\
\hline 23 & $C S^{S} / C S^{H}$ & $30.9352 \mathrm{id}$ & $28.3752 \mathrm{id} 2$ & $59.3752 \mathrm{id} 2$ & $2132.12 \pm 284.9$ & $608.632 \pm 284$ & $2740.75 \pm 284.9 t$ \\
\hline 26 & $C S^{S} / C S^{S}$ & $15.3475 \pm 28$ & $13.8875 \pm 28$ & $29.2275 \pm 28$ & $1968.62 \pm 284.9 \mathrm{t}$ & $357.522 \pm 284$. & $2326.15 \pm 284.9 \mathrm{t}$ \\
\hline 38 & $C S^{S} / C S^{H}$ & $36.1315 \pm 28$ & $50.9915 \pm 284$ & $87.1215 \pm 284$ & $2400.28 \pm 284.9 \mathrm{t}$ & $417.548 \pm 284$. & $2817.82 \pm 284.9 \mathrm{t}$ \\
\hline 39 & $C S^{S} / C S^{H}$ & $17.3482 \pm 284$ & $20.6482 \pm 28$ & $56.97 \pm 30.67$ & 1660.430 .67 .9 & 222.2430 .67 & $1993.720 .67 .9 \mathrm{t}$ \\
\hline 42 & $C S^{S} / C S^{H}$ & 23.1.720. & 30.45720 .6 & 48.93720 .67 & $2584.320 .67 .9 \mathrm{t}$ & 530.2820 .67 .9 & 3114.620 .67 .9 \\
\hline 48 & $C S^{S} / C S^{S}$ & 23.0562 & 14.0862 & 37.1362 & 2679.750 & 363.8450 & 3043.590 \\
\hline 64 & $C S^{S} / C S^{S}$ & 6.25 .590 & 6.46 .590 & 12.71590 .6 & $2233.2 \pm 177.1$ & $335.33 \pm 177.1$ & $2568.52177 .19 t$ \\
\hline 66 & $C S^{S} / C S^{S}$ & 41.4652177 & 38.0652177 . & 79.5252177 . & $1821.85177 .19 \mathrm{t}$ & 476.295177 .1 & $2298.14177 .19 t$ \\
\hline 69 & $C S^{S} / C S^{S}$ & 37.8 .1 & 45.5714 & 83.3714 & 2023.7117 & 368.5611 & 2392.2717 \\
\hline 76 & $C S^{S} / C S^{H}$ & 48.0427177 & 46.1627177 & 94.262717 & $4965.44177 .19 \mathrm{t}$ & $1085.31 \pm 96.63$ & $6050.75 \pm 96.63 \mathrm{t}$ \\
\hline 83 & $C S^{S} / C S^{S}$ & $38.7575 \pm 9$ & 37.72 & $76.4775 \pm 96$ & $4126.75 \pm 96.63$ & $609.025 \pm 96.6$ & $4735.72 \pm 96.63 \mathrm{t}$ \\
\hline 91 & $C S^{H} / C S^{H}$ & $16.8 .72 \pm$ & $4.87 .72 \pm 9$ & $21.6772 \pm 96$ & $3955.06 \pm 96.63 \mathrm{t}$ & $679.286 \pm 96.6$ & $4634.34 \pm 96.63 t$ \\
\hline 93 & $C S^{S} / C S^{H}$ & $2.73 .34 \pm 9$ & $4.31 .34 \pm 9$ & $7.04 .34 \pm$ & $2025.29 \pm 96.63 t$ & $316.079 \pm 96.6$ & $2341.36 \pm 96.63 t$ \\
\hline 96 & $C S^{H} / C S^{H}$ & $18.4936 \pm 9$ & $14.1936 \pm 96$ & $32.6736 \pm 96$ & $1444.06 \pm 96.63$ & $396.946 \pm 96$ & $1841946 \pm 96$ \\
\hline 99 & $C S^{S} / C S^{H}$ & $19.3946 \pm 9$ & $21.7646 \pm 96$ & $41.0646 \pm 96$. & $3352.42 \pm 96.63 \mathrm{t}$ & $620.182 \pm 96.6$ & $3972.62 \pm 96.63$ \\
\hline 102 & $C S^{S} / C S^{H}$ & $27.9 .62 \pm 9$ & $32.3262 \pm 96$ & $60.2262 \pm 96$ & $1358.05 \pm 96.612$ & $185.675 \pm 96.6$ & $1543.71 \pm 96.612$ \\
\hline 105 & $C S^{S} / C S^{H}$ & $24.9271 \pm 9$ & $20.5971 \pm 9$ & $45.5171 \pm 96$ & $2807.51 \pm 96.612$ & $351.311 \pm 96.6$ & $3158.81 \pm 96.612$ \\
\hline 112 & $C S^{S} / C S^{H}$ & $31.9381 \pm 9$ & $42.1681 \pm 96$ & & $2935.99 \pm 96.612$ & $364.329 \pm 96.6$ & $3300.31 \pm 96.612$ \\
\hline 113 & $C S^{H} / C S^{H}$ & $37.1431 \pm 96$ & $38.2731 \pm 96$ & $75.4131 \pm 96$ & $3280.82 \pm 316.12$ & $455.382 \pm 316$. & $3736.22 \pm 316.1$ \\
\hline 116 & $C S^{S} / C S^{H}$ & $25.6522 \pm 31$ & $15.3822 \pm 31$ & $41.0222 \pm 31$ & $1504.93 \pm 316.12$ & $396.943 \pm 316$ & $1901.87 \pm 316.12$ \\
\hline 124 & $C S^{S} / C S^{S}$ & $36.9487 \pm 31$ & $28.2287 \pm 31$ & $65.1687 \pm 31$ & $4521.08 \pm 316.12 \mathrm{e}$ & $416.358 \pm 316$. & $4937.43 \pm 316.12$ \\
\hline 137 & $C S^{S} / C S^{H}$ & $13.0743 \pm 31$ & $15.7843 \pm 31$ & $28.8443 \pm 31$ & $2075.93 \pm 316.1$ & $437.743 \pm 316$. & $2513.64 \pm 316.1$ \\
\hline 138 & $C S^{S} / C S^{H}$ & $50.8464 \pm 31$ & $54.8264 \pm 31$ & $105.664 \pm 316$ & $2436.68 \pm 316.12$ & $511.158 \pm 316$. & $2947.84 \pm 316.12$ \\
\hline 143 & $C S^{S} / C S^{H}$ & $42.0384 \pm 31$ & $54.4884 \pm 316$ & $96.5884 \pm 31$ & $1313.25 \pm 316.12$ & $477.325 \pm 316$. & $1790.57 \pm 316.12$ \\
\hline 144 & $C S^{S} / C S^{H}$ & $41.5357 \pm 19$ & $54.6757 \pm 19$ & $96.2757 \pm 1$ & $2147.34 \pm 196.12$ & $416.634 \pm 19$ & $2563.94 \pm 196.12$ \\
\hline 158 & $C S^{H} / C S^{H}$ & $70.3594 \pm 19$ & $41.3594 \pm 1$ & $111.654 \pm 196$ & $4570.33 \pm 196.12$ & $625.233 \pm 196$. & $5195.55 \pm 196.12$ \\
\hline 162 & $C S^{S} / C S^{H}$ & $35.6255 \pm 19$ & $48.5755 \pm 19$ & $84.1855 \pm 19$ & $2381.47 \pm 196.12$ & $313.657 \pm 196$ & $2695.13 \pm 196.12$ \\
\hline 164 & $C S^{S} / C S^{H}$ & 18.0213 & 12.2213 & 30.2413 & $1295.06 \pm 1$ & $518.116 \pm$ & $1813.17 \pm 1$ \\
\hline 169 & $C S^{H} / C S^{H}$ & $37.6217 \pm 19$ & $3.0917 \pm 19$ & $90.7117 \pm 19$ & $2488.37 \pm 196.12$ & $310.027 \pm 196$. & $2798.47 \pm 196.1$ \\
\hline 170 & $C S^{S} / C S^{H}$ & $104.647 \pm 196$ & $28.8747 \pm 19$ & $133.477 \pm 196$ & $1234.92 \pm 196.12$ & $250.792 \pm 196$ & $1485.61 \pm 196.12$ \\
\hline 172 & $C S^{S} / C S^{H}$ & $14.75 \pm 7.74$ & $38.59 \pm 7.746$ & $53.33 \pm 7.74$ & 1490.46 .746 .12 & 291.666 .746$. & 1782.12 .746 .12 \\
\hline 176 & $C S^{H} / C S^{H}$ & 33.7912 .74 & 33.5812 .74 & 67.3712 .746 & 1967.44 .746 .12 & 347.384 .746 . & 2314.81 .746 .12 \\
\hline 187 & $C S^{H} / C S^{H}$ & 11.7481 .74 & 12.1981 .74 & 23.9481 .746 & 1607.09 .746 .1 & 244.929 .746$. & 1852.02 .746 .1 \\
\hline 189 & $C S^{S} / C S^{H}$ & 111.742 .746 & 46.174 & 157.832 .746 & 2026832.746 & 445.222 .746 & 2471.22 .746 .12 \\
\hline 190 & $C S^{S} / C S^{S}$ & 39.8222 .74 & 71.5222 .7 & 111.322 .746 & 1841.77 .746 .12 & 339.517 .746 . & 2181.28 .746 .12 \\
\hline 195 & $C S^{S} / C S^{S}$ & 22.1728 .74 & 26.6128 .746 & 48.7828 .746 & 2160.44 .746 .12 & 382.494 .746 . & $2542.93 \pm 242.4$ \\
\hline 204 & $C S^{H} / C S^{H}$ & $63.7493 \pm 242$ & $54.3793 \pm 242$ & $118.113 \pm 242$ & $2408.69 \pm 242.42$ & $348.919 \pm 242$ & $2757.59 \pm 242.42$ \\
\hline 205 & $C S^{S} / C S^{H}$ & $27.3759 \pm 24$ & $56.5359 \pm 242$ & $83.9159 \pm 242$ & $1890.82 \pm 242.4$ & $419.542 \pm 242.4$ & $2310.35 \pm 242.42$ \\
\hline 213 & $C S^{S} / C S^{S}$ & $31.3635 \pm 24$ & $45.6335 \pm 24$ & 77.6335 & $1998.59 \pm 242.42$ & $311.94 \pm 33.04$ & 2310.5333 .0442 \\
\hline
\end{tabular}

Capsaicinoid and capsinoid concentration at 30 days after fruit set was measured. Four plants $(22,51,134$ and 184$)$ were not determined. * indicates that this experiment was not repeated. $S$ : SNU11-001 $H$ : Habanero. 
in high levels of capsinoid in $\mathrm{F}_{2}$ plants.

In this study we identified and used a pepper accession C. chinense 'SNU11-001'. cDNA sequence structure of SNU11-001 is similar to Aji Dulce strain 2 in that SNU11001 has Tcc element in third intron and $8 \mathrm{bp}$ insertion (Tanaka et al.2010b). However, SNU11-001 is distinguished from Aji Dulce strain 2, since SNU11-001 has additional 45 bp deletion and remarkably higher capsinoid content as compared to Aji Dulce strain 2. Furthermore, capsinoid content was higher because it was measured in whole fruits of SNU11-001 while it was extracted from placenta and seeds in Aji Dulce strain 2 (Tanaka et al. 2010b). It is expected that SNU11-001 would be useful for breeding cultivars with high capsinoid content.

A similar study was reported by a Japanese research group (Tanaka et al. 2014). A cultivar named 'Maru Salad' was developed by crossing non-pungent pepper 'Murasaki' and 'CH-19 Sweet' which also has a dysfunctional $p A M T$ allele. This cultivar contains approximately $700 \mu \mathrm{g} / \mathrm{gDW}$ capsinoid, which is much lower than those of ' $\mathrm{CH}-19$ Sweet' $(5825 \pm 286 \mu \mathrm{g} / \mathrm{gDW})$ and of $\mathrm{F}_{2}$ plants derived from SNU11-001. In this study, Habanero was selected to generate a population because of its high levels of capsaicinoid. It was assumed that the strong CS activity of Habanero causing high content of capsaicinoid could also contribute to capsinoid content.

However, we cannot rule out other factors that are also involved in the control of capsinoid content because plants with $C S^{S} / C S^{S}, C S^{H} / C S^{H}$ and $C S^{S} / C S^{H}$ contained almost similar concentration of capsinoid (3033.95 \pm 383.82 $\mu \mathrm{g} / \mathrm{gDW}, 2622.69 \pm 207.26 \mu \mathrm{g} / \mathrm{gDW}$ and $2933.66 \pm 309.53$ $\mu \mathrm{g} / \mathrm{gDW}$, respectively). Other genes in capsaicin or capsinoid pathway could be Pal, Ca4h, Comt, and Kas (Curry et al. 1999; Aluru et al. 2003). If the factors causing high capsaicinoid content in Habanero had have the same effect on capsinoid content, QTL responsible for capsaicinoid might also control accumulation of capsinoid (Blum et al. 2003; Ben-chaim et al. 2006). For further study, $F_{2}$ populations using SNU11-001 and other cultivars with various pungency levels need to be developed to validate the relationship between $C S$ expression levels and capsinoid content.

\section{ACKNOWLEDGMENTS}

This work was supported by a grant (code: 710001-07) from the Vegetable Breeding Research Center through R\&D Convergence Center Support Program, Ministry for Food, Agriculture, Forestry and Fisheries and by the Next-Generation BioGreen 21 Program (Plant Molecular Breeding Center, No. PJ01120501), Rural Development Administration, Republic of Korea.

\section{REFERENCES}

Ben-Chaim A, Borovsky Y, Falise M, Mazourek M, Kang BC, Paran I, and Jahn MM. 2006. QTL analysis for capsaicinoid content in Capsicum. Theor. Appl. Genet. 113: 1481-1490.

Curry J, Alure M, Mendoza M, Nevarez J, Melendrez M, O'connel MA. 1999. Transcripts for possible capsaicinoid biosynthetic genes are differentially accumulated in pungent and non-pungent Capsicum spp. Plant Sci. 148: 47-57.

Del Rosario Abraham-Juarez M, Del Carmen RochaGranados M, Lopez MG, Rivera-Bustamante RF, OchoaAlejo N. 2008. Virus-induced silencing of Comt, pAmt and $K A s$ genes results in a reduction of capsaicinoid accumulation in chili pepper fruits. Planta. 227: 681-695.

Han K, Jeong HJ, Sung J, Keum YS, Cho MC, Kim JH, Kwon JK, Kim BD, Kang BC. 2013. Biosynthesis of capsinoid is controlled by the Punl locus in pepper. Mol. Breeding. $1-12$.

Lang Y, Kisaka H, Sugiyama R, Nomura K, Morita A, Watanabe T, Tanaka Y, Yazawa S, Miwa T. 2009. Functional loss of $p A M T$ results in biosynthesis of capsinoid, capsaicinoid analogs, in Capsicum annиит cv. CH-19 Sweet. Plant J. 59: 953-961.

Nelson EK, Dawson LE. 1923. The constitution of capsaicin, the pungent principle of Capsicum. III. J. Am. Chem. Soc. 45: 2179-2181.

Sharma SK, Vij AS, Sharma M. 2013. Mechanisms of clinical uses of capsaicin. Eur J. of Pharm. 720: 55-62.

Tanaka Y, Hosokawa M, Miwa T, Watanabe T, Yazawa S. 2010a. Newly mutated putative-aminotransferase in nonpungent pepper (Capsicum anmuum) results in biosynthesis 
of capsinoid, capsaicinoid analogues. J. Agric. Food Chem. 58: 1761-1767.

Tanaka Y, Hosokawa M, Miwa T, Watanabe T, Yazawa S. 2010b. Novel loss-of-function putative aminotransferase alleles cause biosynthesis of capsinoid, nonpungent capsaicinoid analogues, in mildly pungent chili peppers (Capsicum chinense). J. Agric. Food Chem. 58: 1176211767.

Tanaka Y, Hosokawa M, Hosokawa M, Miwa T, Yazawa S. 2014. Application of marker-assisted selection in breeding of a new fresh pepper cultivar (Capsicum anmuиm) containing capsiniod, non-pungent capsaicinoid analogs. Sci Hortic.
165: 242-245.

Thiele R, Mueller-Seitz E, Petz M. 2008. Chili pepper fruits: presumed precursors of fatty acids characteristic for capsaicinoid. J. Agric. Food Chem. 56: 4219-4224.

Xiu-Ju L, Jun P, Yuan-Jian L. 2011. Recent advances in the study on capsaicinoid and capsinoid. Eur. J. Pharmacol. 650: 1-7.

Yazawa S, Suetome N, Okamoto K, Namiki T. 1989. Content of capsaicinoid and capsaicinoid-like substances in fruit of pepper (Capsicum annuum L.) hybrids made with 'CH-19 Sweet' as a parent. J Jpn Soc Hort Sci. 58: 601607. 